\title{
The Influence of Sharing Evaluation Information on Consumer Buying Behavior in Social Commerce
}

\author{
Bo Shen, Liang Tai and Dan Liu \\ School of Information Technology, Jiangxi University of Finance and Economics \\ Nanchang, Jiangxi, China \\ jxcdsb@163.com, tailiang2004@163.com,ldfrency@126.com
}

\begin{abstract}
Social commerce is a new generation of e-commerce. Compared to traditional commerce, social commerce, treating social media and social network as a carrier, promotes online trading and information exchange related to commercial activities. Information sharing in social commerce affects buying behavior of consumers in all aspects. Therefore, research on information sharing in social commerce has important implications for further investigation in consumer behavior and business marketing strategy. In this paper, the authors propose a method of multi-agent simulation based on FIRE model, to discuss the influence of sharing evaluation information on consumer buying behavior in social commerce. This study established a simulation model of consumer behavior based on the information, took full account of the effect given by situational factors and information sources, set up rules on consumer decision of purchase on the basis of consumer sub-model and merchant sub-model, realized the simulation for two different information sharing situation by using Repast, and drew relevant conclusions according to simulation results about the total number of transactions and trading volatility of each type of merchants.
\end{abstract}

Keywords: Social commerce, Information sharing, Customer behavior, Multi-agent simulation, Repast

\section{Introduction}

With the rise of SNSs and social apps such as microblog, RenRen, Wechat, ecommerce based on virtual community platform is often referred to social commerce(scommerce). Social commerce is considered as e-commerce with the use of social media. It is a collection of commerce and social activities [1]. Social commerce is a new generation of e-commerce.

Compared to traditional commerce, social commerce, treating social media and social network as a carrier, promotes online transactions and information exchange related to commercial activities [2]. Sharma et al. believed that in traditional e-commerce environment, consumers' transactions are limited to a certain website [3]. The difference is that, in the s-commerce environment, consumers continue to mutually share their reviews, buying preferences and suggestions feedback. Consumers are no longer just passive recipients of information, but also become influencers - influencing the behavior of other consumers. Synthesizing these scholars' views above, we believe that social commerce includes all participants' commercial exchange activities and information sharing. Social commerce contains two basic elements, namely social media and business activities.

In recent years, social networking has become the main trend of e-commerce. The development of foreign social commerce mainly experiences several phases: online group purchasing represented by Groupon, micro-blog marketing on the platform of Twitter, internet marketing and social shopping on the platform of SNS, etc. By 2015, the market 
size of American social commerce will reach to $\$ 30$ billion [4]. Compared with foreign countries, the market size of domestic social commerce is relatively small. Domestic social commerce website is mainly to add the social applications in traditional ecommerce website and only a few websites think highly of social networking and ecommerce equally. But with the booming of social networking applications such as WeChat, the integration of online shopping into social network media has gradually become the main trend of the development of the Chinese social commerce. For example, many merchants by registering WeChat accounts or micro-blog accounts, share product information and consumer's review in the social circle to achieve marketing purpose through social networks.

The social commerce is composed of social interaction, online business consumers, other social network elements and the sharing of product information or advice [6]. The sense of contribution to the online community will motivate person to share information continuously, and these information would affect the behavior of others in the community. According to study of Eric (www.iresearch.com), with the e-commerce socializing, the behaviors of consumers also change significantly. In s-commerce, consumers are more concerned about views from "friend", and become more convinced of evaluation information from "friend" because of the suspection about vendors' advertisements. Meanwhile, the s-commerce activities, to some extent, reshape the user's social relationships and play a significant role in promoting the dissemination of goods or services. Briefly, the sharing of information in s-commerce affects the buying behavior of consumers in all aspects [6]. Thus, the study of information sharing in s-commerce is of great significance for the research of consumer's behavior and the formulation of the marketing strategy.

The information sharing in s-commerce is a dynamic process, and information's sharing and transmission must rely on the social network. If we just adopt static analysis to analyze the data within a certain point of time or a certain period of time, rather than evolutionary analysis, the results will have deflections and limitations. Therefore, this paper puts forward a multi-agent simulation based on FIRE model taking the process of choosing commodity or service after gaining evaluation information for example, in terms of micro factors such as consumers, situation and trust, then abstracting behavior rules and building the information-based model of consumer buying behavior.

By simulating different information-sharing situations, and studying the interaction of consumers and merchants, this paper aims to achieve the simulation analysis and forecast of consumer buying behavior in s-commerce. And the simulation data will be helpful to further support the study of social commerce. The method in this study belongs to a way of ex-ante forecasting.

\section{The Construction of the Model}

\subsection{The Model's Structure}

This paper took the process of consumer decision of purchase goods or services in scommerce for example, focused on the impacts of other consumers' assessment information in the social network, real-time situation and the types of businesses on consumer buying behavior, and analyzed the characteristics of consumers' purchase activities under different information sharing situations, several entities including vendors, consumers, goods, situation, involved. Conceptual model is as shown in Figure 1. 


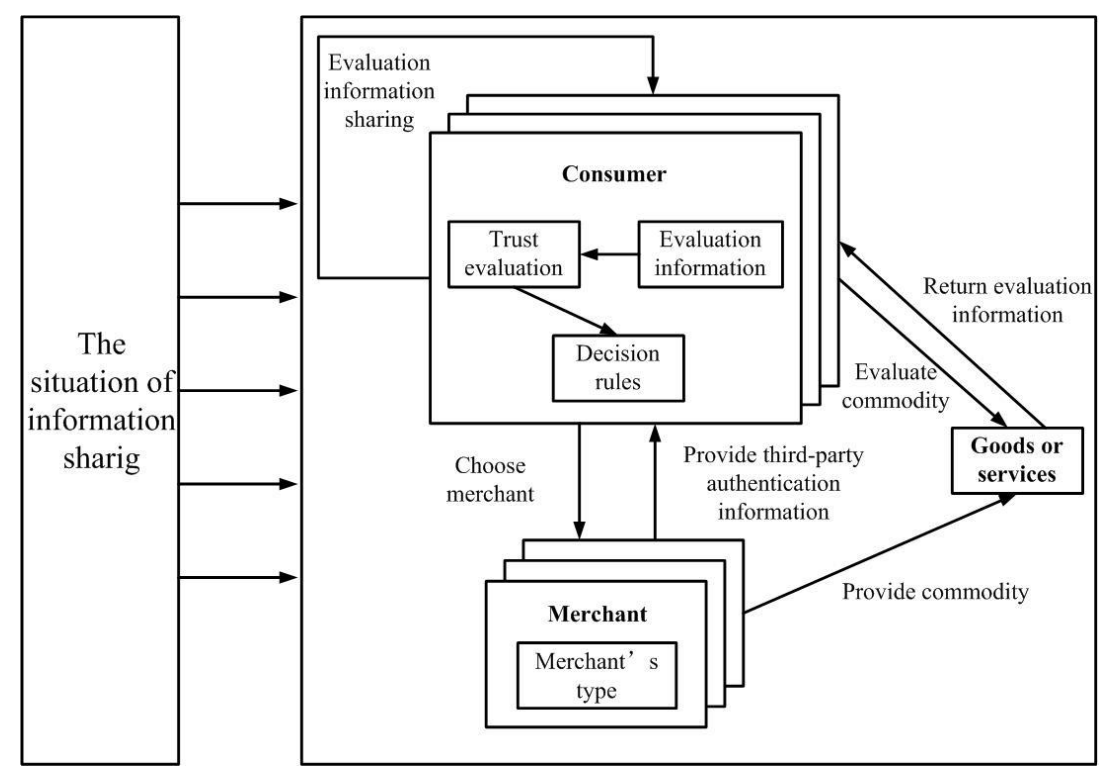

Figure 1. Conceptual Model

Social sharing is different from traditional evaluation browsing. Sharing in s-commerce takes users' social network as the path, such as sharing among friends, but the traditional browsing online evaluation of customers can only be regarded as sharing with strange consumers. According to a survey of s-commerce [7], 83\% of online consumers are willing to share with friends in shopping information, and $67 \%$ of online consumers are more likely to buy those goods which friends has recommended. Information shared by friends is considered by consumers as more valuable information, which plays a crucial role in the social commerce [8]. Wu [9], etc. found interactive activities, including purchase, can cultivate and sustain the online relationship among users, strengthen the trust of users in s-commerce, because similar behavior can enhance the identity among them. According to the above conclusion, this study is based on the following assumptions:

- All entities are willing to share their shopping experiences with other entities;

- Exchange of information between entities is honest;

- Social connections between the consumers with the same purchase preference can be established or strengthened.

According to the realistic situation and the finiteness of consumer knowledge, it is impossible to be completely rational for consumer's behavior. At the same time in order to simplify the complexity of research, the model will be based on the following assumptions:

- Trust is the main basis of consumer decision but there also exists a certain randomness;

- Merchants in the model provide the same type of commodities or services

In multi-agent simulation modeling, usually entities that have obvious characteristics of autonomy and intelligence would be treat as subjects (agents) and others would be regarded as objects. Therefore, the model in this paper has these entities including consumers, merchants, and situation, but goods are described as subjects.

\subsection{Fire Model}

FIRE model is a kind of trust model based evaluation information of multi-agent system, which conducts a comprehensive prediction on the agent in multi-agent system by integrating various types of evaluating information [10]. In FIRE model, if the single agent's information about the environment and other agents is limited, trust will be the 
main basis for the occurrence of these agents to interact. Trust can be seen as an expectations or beliefs on the targeted agent for the evaluator: the behavior of the targeted agent was friendly and reliable.

In short, the FIRE model concludes the types of evaluation information that can affect the trust in multi-agent system, and quantitatively analyze the trust based on the evaluation information, deduces the formulas for calculating trust degree:

$$
T_{K}(a, b)=\frac{\sum_{\gamma_{i} \in R_{K}(a, b)} \omega_{\mathrm{K}}\left(\gamma_{i}\right) * v_{i}}{\sum_{\gamma_{i} \in R_{K}(a, b)} \omega_{\mathrm{K}}\left(\gamma_{i}\right)}
$$

$T_{K}(a, b)$ means the value of the trust based on the type $\mathrm{K}$ of evaluation information about the merchant $\mathrm{b}$ from the customer $\mathrm{a} ; \gamma_{i}$ means evaluation information, and the evaluation can be expressed by $\gamma_{i}=(a, b, i, v)$, while a and $\mathrm{b}$ represent the two main interactive participants, a denotes evaluating customer, $b$ represents the merchant objective, i represents a particular transaction, and evaluation value $v_{i}$ represents the quantitative evaluation on the behavior of merchant objective from customer in the transaction $i$, taking value in the range $[-1,1]$, where 1 means very satisfied, -1 means very dissatisfied. $\gamma_{i}$ would be evaluated comprehensively after every transaction in terms of product appearance, performance, quality and so on. $\omega_{K}\left(\gamma_{i}\right)$ represents the weight denoting the impact of information $\gamma_{i}$ on trust. Different types of information have different impacts on the trust, which should be defined separately under specific research areas.

At the same time, FIRE model insist that interactive strategy of principals is "exploredevelopment" in multi-agent system, which means each subject initially tend to explore the environment that it's situated in, and then it will gradually tend to develop environment instead of exploring when having more knowledge of its environment.

$$
P\left(a_{K}\right)=\frac{e^{\frac{E R\left(a_{K}\right)}{T}}}{\sum a_{i} e^{\frac{E R\left(a_{i}\right)}{T}}}
$$

$P\left(a_{K}\right)$ represents the probability of the subject choosing interactive strategy $a_{K}$, which $a_{K}$ has two type, namely exploring and developing. $E R\left(a_{K}\right)$ indicates the expectation of consumer if choosing $a_{K} . \mathrm{T}$ is the time parameter, which means the number of choosing developing increases and the number of choosing exploring decreases over time.

Through case studies, it has proved that the FIRE model has better performance compared with traditional SPORAS credit model [10-11]. At the same time the FIRE model can be applied to a series of situations and provide accurate enough credit measurement [12].

\subsection{The Applicability of FIRE Model for this Study}

In s-commerce, consumer behavior is affected not only the advertisement, publicity, reputation of retailers, but also influenced by other consumers in a friend relationship within social networks. Consumers can cooperate with each other online, exchange information about the goods and services they trust with individuals in social networks, so that they can make more accurate purchasing decisions [13]. Therefore, social commerce can be seen as a multi-agent system consisting of a number of agents: in the system each agent share information and join in business activities, and they have different 
personalities, educational background, preferences, tendencies, and social tendencies. Not only in the real world will people invite acquaintances to join the community, but there will be some combination of the members who are strangers, after a period of communication to understand each other. The interactions between agent and agent, between agent and environment form complex nonlinear networks. Both the behavior of individuals involved in the system, and the way information is shared have a variety of options, making the buying behavior of consumers in s-commerce appear characteristics of diversity.

Furthermore, the relationship in social networks among consumers and the behavior in social commerce interact with trust as an intermediary. Merchants and consumers regard trust as a link. Trust is likely to increase consumer willingness to buy, playing a vital role in e-commerce consumer decision-making $[14,15]$. Chang [16] proposed that mutual trust is a major factor for the interaction between buyers and sellers within business success, in any e-commerce, including s-commerce, and these interactions are also the basis for merchants to achieve business objectives. Zhang, etc. believed social commerce environment that exhibits a greater level of sociability may increase social interactions and create stronger feelings of trust. Meanwhile, Bock [18] found that some information about merchants which spreads through social networks will enhance the goodwill and trust of consumers. After the purchase of goods or receiving services, the gap between consumers' satisfaction and expectations will affect the relationship of trust on merchants, what's more, making the original s-commerce relationships based on trust disappear, thus forming new relationships.

To sum up, the activities about consumers' decisions of purchase in s-commerce could be considered as the interaction on the basis of trusting a multi-agent system. This is entirely viable to analyze and simulate by using the FIRE model.

\subsection{The Construction of Agent Model}

In this study, the authors take consumer buying behavior based on evaluation information as the main object of study, and analyze the influence of sharing evaluation information on consumer buying behavior by the FIRE model. Therefore, this paper regards the consumer as evaluating subject of credit assessment and the merchant as target subject of credit assessment.

1) The consumer sub-model

These factors affecting trust evaluation of consumers who are assessment agents for entire system include: direct experience, witnessing information, rules, policies, and so on. Although there are many sources of information that can affect the formation of trust, this study insists that the information can be divided into four main factors with the evaluation function, namely:

a) Evaluation information based on the experience of direct transaction

Consumers form trust assessments about their interaction agent, according to evaluation information based on previous transaction experience. That type of trust is called interaction trust.

b) Evaluation information based on the role relationship

This evaluation information is based on a variety of relationships among consumers or consumer's specialist knowledge about his surroundings. For example, two customers belonging to the same department may trust each other all the time. This trust formed because of role relationship is called role-based trust.

c) Evaluation information provided by other consumers in range of social activities

Consumers are willing to share information about shopping experience. So the assessment body can collect information of all the consumers in range of social activities, in order to assess the degree of trust on the target merchant precisely. This type of trust is known as shared trust. 


\section{d) Evaluation information based on the third-party certification}

The three preceding evaluation information needs the initiative collection of consumers. But at the same time, merchants will take the initiative to provide consumers with a certain trust certification. This certification can be made by customers who have shopping experience with this merchant or designated authority to prove the reliability of merchant. Compared with other information, without collecting information by himself, the consumer can easily get information through a simple interaction before the transaction, without constraints of time or knowledge, and other factors. This trust based on such information is called certification trust. This research focuses on interaction trust and shared trust, and puts others as the research direction in the future.

This study defines interaction trust as $T_{I}$, shared trust as $T_{S}$. Similar to people's cognitive, early assessment information may become "outdated", and the weight to the impact of the latest assessment information on trust degree will be bigger than the early evaluation information. So we can define the weight to the impact on trust from evaluation information based on interaction trust $T_{I}$, as follows:

$$
\omega_{I}\left(\gamma_{i}\right)=e^{-\frac{\Delta t\left(\gamma_{i}\right)}{\sigma}}
$$

$\omega_{I}\left(\gamma_{i}\right)$ represents the weight to the impact of evaluation information $\gamma_{i}$ in interaction trust. $\Delta t\left(\gamma_{i}\right)$ denotes the difference between the assessing time and the recorded time when evaluation information occurs. I represents the type of interaction trust. The weight $\omega_{I}\left(\gamma_{i}\right)$ to evaluation information in interaction trust, has negative correlation with $\Delta t\left(\gamma_{i}\right)$, and $\omega_{I}\left(\gamma_{i}\right)$ can make interaction trust more rapidly reflect the change of merchants' behavior. The quality of products or service that merchants provide has deteriorated, for example. Parameter $\sigma$ represents the value of time utility for evaluation information. For instance, if for trust evaluating body the assessment information 5 days ago has half the utility of the latest assessment information, we can define $\sigma$ as follows: $\sigma=-\frac{5}{\ln (0.5)}$.

Shared trust is built on the evaluation information that other consumer provide. In scommerce, information sharing would take the approach similar to the infection of biological virus, which some observations and researches have proved [19]. Some consumer's evaluation information can be gained by his friend and a friend of his friend and this information seem to be more valuable. Actually consumers share assessment information in traditional e-commerce, but the strangeness of consumers has pushed spreading scope decrease with the value of evaluation information. In this study, consumer could obtain the evaluation information from others in his social network which is passed by consumers in the intermediary role. In real situation, each consumer who is subject to the limitation of his memory capacity, communication cost, social tendencies and other factors, has distinct social scope. Meanwhile, consumers need to complete the interaction with merchants in a limited time. As a result, when evaluating trust, consumer cannot make one query to all the assessment information from others in his social network. Consequently, this paper sets parameter Radius as the radius of consumer's social circle, sets parameter as the maximum number of others the consumer queries, and sets parameter as the maximum length of query chain, in another word, it's the maximum number of consumers each query.

The reason why this paper need set the maximum length of query chain is that the evaluation information from consumer with less connection is unreliable for searcher. 


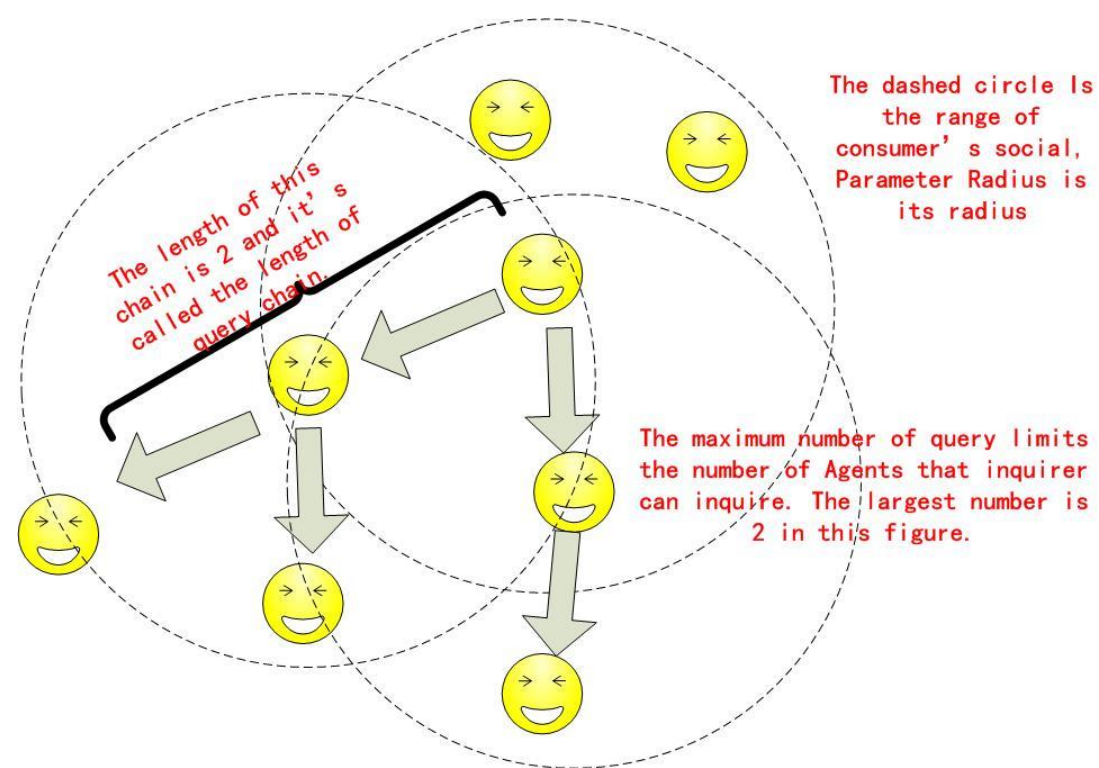

Figure 2. The Query In Shared Trust

The process of the query to evaluation information in shared trust is: consumer a makes queries to $n_{B F}$ consumers in range of social activities about evaluation information sets of merchant $\mathrm{b} ; n_{B F}$ consumers not only feed back previous evaluation information about merchant $\mathrm{b}$ to consumer $\mathrm{a}$, but also continue to query to $n_{B F}$ consumers in range of their social activities, while $n_{R F}$ indicates the length of query chain. Assuming that each consumer is honest in this study and completely convinced of assessment information which are based on other consumers' experience of direct transaction, evaluation information based on interaction trust is as effective as evaluation information based on shared trust. So we define the weight to the impact on trust from both as follows: $\omega_{I}\left(\gamma_{i}\right)=\omega_{S}\left(\gamma_{i}\right)$.

2) The merchant sub-model

In this study, merchants provide consumers with services or goods, consumer feedback quality of goods or services and share information in social networks. This study focuses on the impact of information sharing situations on consumer buying behavior, so the type and distribution of merchant, quality of goods or service can be regarded as controlled variables of simulation to study consumer behavior. This paper overly simplified merchants with three types of merchants, namely Good, Ordinary, Bad. When transaction occurs in each unit of time, a randomly generated number in designated continuum on the basis of the type which merchant belongs would reflect the quality of products or service in this transaction, resulting in the generation of corresponding assessment information from consumers according to this number. The difference of merchant's types is due to the distinct cost performance of products or service. High-quality merchant would provide cost-effective products and quality service. Otherwise, products or service that inferior merchant provides are low performance. Because of the random distribution of merchants in the simulation space, the number of all types of merchants is normally distributed, which is similar to reality [20]. Meanwhile, in the real e-commerce platform, consumers can often quickly find the provider of required service or goods by using the search function. With the assumption of perfect search recommendation system, when consumer asking for service, the system would notify each consumer of the relevant information, and make consumers know the position information of all merchants in the system. 


\section{The Rules of Interaction}

The rules of merchants' interaction are that for each consumer requesting a transaction, a corresponding random value QS to represent the quality of merchant's services is generated. The total range of QS is $[-10,10]$, while the range of quality merchants' QS is $(5,10]$, the range of inferior merchants' $\mathrm{QS}$ is $[-10,0]$ and the range of ordinary merchants' QS is $(0,5]$. In real life, merchants cannot always guarantee the quality of service or goods matching its type: high-quality merchants sometimes have poor performance at transaction, while poor merchants may provide quality services in some transactions. Therefore, this study sets a probability $P_{\text {convert }}$ for the change of merchant's type: before every transaction, every merchant converts to other types of merchants with certain probability $P_{\text {convert }}$, and restores its original type after the completion of transaction.

The interaction among consumers is information sharing. In s-commerce situation, evaluation information is generally shared in social network. So consumers only share information with other consumers who are in range of their social network. In this study the factors that influence the formation and disappearance of social relations in scommerce are not considered. Beside social relationship among consumers is randomly formed and dynamic. The radius of social network is defined as parameter Radius.

The consumer agents' selection of merchants is based on the trust degree which is evaluated by the consumer sub-model. Specific selection rules are as follows:

- In the simulation of consumer agent, the probability of occurrence of transactions per time unit is set to parameter $P_{\text {demand }}$.

- After the transaction, consumers will evaluate all known merchants' trust degree. These merchants, who cannot be evaluated due to the lack of comments, are classified into merchants set $S_{\text {NoTrust }}$ and the rest are classified into merchants set $S_{\text {HasTrust }}$.

- After the evaluation, consumer have two choice including $a_{1}$ and $a_{2}$.

$a_{1}$ : Consumer chooses the merchant who has highest trust degree in the $S_{\text {HasTrust }}$. Because in this model, higher trust degree means better product and service.

$a_{2}$ : Consumer chooses a merchant randomly from $S_{\text {HasTrust }}$. This can be considered as a further learning of the social commerce environment.

- If $S_{\text {HasTrust }}$ is empty set, the consumer only have to choose $a_{2}$.If $S_{\text {NoTrust }}$ is empty set, the consumer only has to choose $a_{1}$.

- When both $S_{\text {HasTrust }}$ and $S_{\text {NoTrust }}$ are not empty, consumer have to make a choice between $a_{1}$ and $a_{2}$. Option $a_{1}$ can help consumer find more merchants and know more about merchants' types. But this choice perhaps leads to a transaction with Bad merchant. On the contrary, option $a_{2}$ can help consumer obtain the best quality product and service from all known merchants. But because of the limited rationality and the restriction on environmental awareness, consumers' choice may not always be optimal.

In this paper, exploring behavior is defined as a random selection from merchants in $S_{\text {NoTrust }}$ and developing behavior is defined as choosing the merchant who has the highest trust degree from $S_{\text {HasTrust }}$. The expectation of option $a_{1}$, namely $\operatorname{ER}\left(a_{1}\right)$ is the latest assessed value of merchant with highest trust degree. The expectation of option $a_{2}$, namely $E R\left(a_{2}\right)$ is the mean value of all known merchants' trust degree. This paper 
puts consumer preference aside, so after the interaction with the target merchant, the consumer can directly give the evaluation value of this transaction according to the value of QS.

\section{The Implementation and Simulation of the Model}

\subsection{The Implementation of The Model}

In this paper, the model is realized by the multi-agent simulation platform REPAST with the version of REPAST Simphony 2.1 and the Java programming language. The custom library involved in this model can be divided into two categories: entity class library and function libraries. Entity class libraries can generate different buying strategy according to the rules of consumer behavior, and define the attributes of consumer agent and merchant agent and their respective rule base. Function libraries are responsible for implementing the basic two-dimensional model, setting initial and operational parameters, managing the starting, running and ending of the model.

\subsection{The Analysis of Simulation Result}

This paper proposes to simulate the consumers' choice behavior in s-commerce with a method of multi-agent simulation. The initial parameters are set as shown in Table 1. There are always a few cost-effective merchants in real situation, so we assume the number of cost-effective merchants whose type is set to Good is far lower than the other two types of merchants.

Table 1. The Setting Of Initial Parameters

\begin{tabular}{|c|c|}
\hline Initial Parameters & Value \\
\hline Total time of simulation & 300 \\
\hline $\begin{array}{c}\text { the number of Good } \\
\text { merchants }\end{array}$ & 1 \\
\hline $\begin{array}{c}\text { the number of Ordinary } \\
\text { merchants }\end{array}$ & 6 \\
\hline $\begin{array}{c}\text { The number of Bad } \\
\text { merchants }\end{array}$ & 200 \\
\hline The number of consumers & $-\frac{5}{\ln (0.5)}$ \\
\hline$\sigma$ & 0.8 \\
\hline$P_{\text {demand }}$ & 0.1 \\
\hline$P_{\text {convert }}$ & 10 \\
\hline $\mathrm{H}$ & \\
\hline
\end{tabular}

In addition, in order to comprehensively inspect the influence of social relationships on consumers' choice behavior, this study was carried out in two simulation situations, including traditional-information-sharing environment in e-commerce and information sharing environment in s-commerce. Through the comparison of two schemes, the characteristics of consumer choice behavior in the two types of business model are evaluated and compared.

The authors analyzed the sum total of the number of goods or services provided by each type of merchants and the sum total of the number of consumers who were provided simultaneously with goods or services by each type of merchants at a certain point in time. The sum total of the number of goods or services provided by each type of 
merchants is actually the gross sales of each type of merchants, because the transaction has happened when merchant provides with goods or services. The sum total of the number of consumers who were provided simultaneously with goods or services by each type of merchants at a certain point in time reflects the volatility of the number of transactions.

4.2.1. The Analysis of Consumer Buying Behavior In Traditional E-Commerce: In this simulation scheme, consumers share information with others they don't know, so the social relationship is relatively weak. Consumer can only see reviews information of his friends, but could not get information from others in his friend's social network. Therefore, this simulation scheme sets parameter Radius as 2, parameter $n_{R F}$ as 0 , parameter $n_{B F}$ as 10, and the simulation result is as shown in Figure 3.

\section{Informtion Sharing of Tranditional E-Commerce}

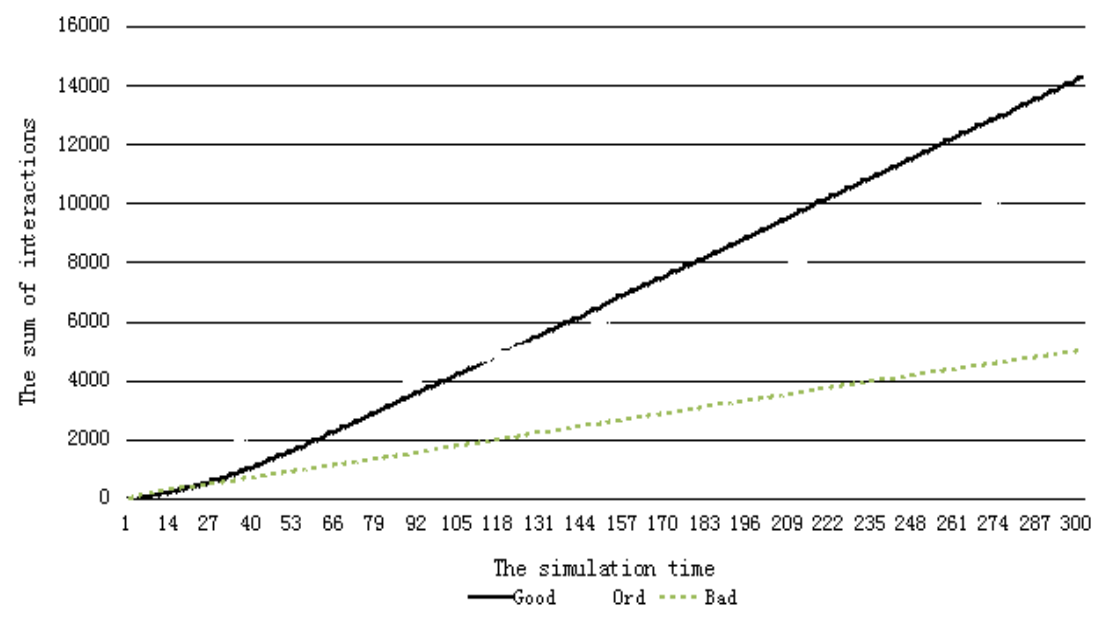

Figure 3. The Total Trading Volume (Traditional E-Commerce)

Figure 3 illustrates the total trading volume in traditional e-commerce, while the horizontal axis shows the simulation time and the vertical axis displays the number of transactions. It can be seen from Figure 3 that in e-commerce consumers can still distinguish the types of merchants according to past trading evaluation information. Good merchants gets much less total sum of transactions at the beginning of the simulation because of quantitative inferiority. Consumers adopt exploring strategy in the beginning, so the probability of Good merchants for being explored is small compared to others. As consumers get enough information, the benefits of Good merchants become apparent. 


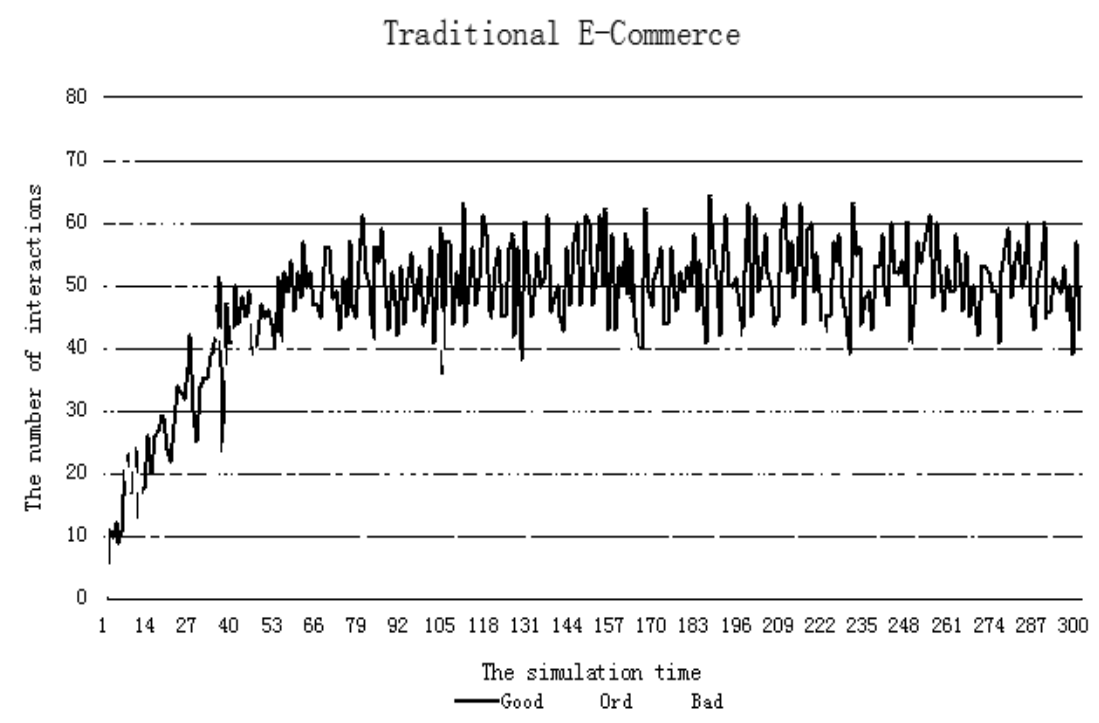

Figure 4. The Volatility of Transaction Times (Traditional E-Commerce)

Figure 4 illustrates the volatility of transaction times in e-commerce, while the horizontal axis shows the simulation time and the vertical axis displays the number of consumers who are dealing with merchants. Figure 4 reflects the trend of Figure 3: merchants providing quality goods or services always have more consumers than others. Once consumers have enough information, the number of consumers served by highquality merchant will surge and that served by other merchants will drop. After some time, there exists fluctuation on the number of consumers serviced by all types of merchants, but the fluctuation range is kept at a stable level. The average number of transaction is proportional to the cost of goods and services offered by merchants. This paper insists there are two main reasons for unstable transaction times: on the one hand, the active probability of consumers $P_{\text {demand }}$ cause consumers not to purchase in each simulation time; on the other hand, some consumers adopt exploring strategy (select a merchant of $S_{\text {NoTrust }}$ at random) instead of developing strategy (choose the most trustworthy merchant of $S_{\text {NoTrust }}$ ). In this scheme, the great volatility of the number of transactions early is because the cognition about environment of consumers is very limited in e-commerce, and the expectations $E R$ are basically the same in whatever strategy. So the strategy consumer adopts would be changed frequently.

It turns out information sharing makes the choice of consumers become unified. Consumers tend to continue trading with quality merchants finally. As can be seen from the figure, although there are fluctuations in the number of consumers served by all types of merchants within a fixed range, the average level has not large difference. This means although dominant in total sales, quality merchants have no obvious gap with other merchants in market share.

4.2.2. The Analysis of Consumer Buying Behavior In s-Commerce: In this simulation scheme, evaluation information is shared with consumers, and spread through the path of information sharing within a certain range of social network. The radius of consumer's social circle determines the quantity and speed of his collecting information. This paper puts aside any considerations for the difference of every consumer' social range, which is a project we can research continuously. The support of social media enlarges the scope of consumer's social circle compared to traditional e-commerce. As the length of query chain increases, the number of queried consumers is increasing. So this simulation 
scheme sets parameter Radius as 2.0, parameter $n_{R F}$ as 2, parameter $n_{B F}$ as 3 . The result of simulation is shown in Figure 5 and Figure 6.

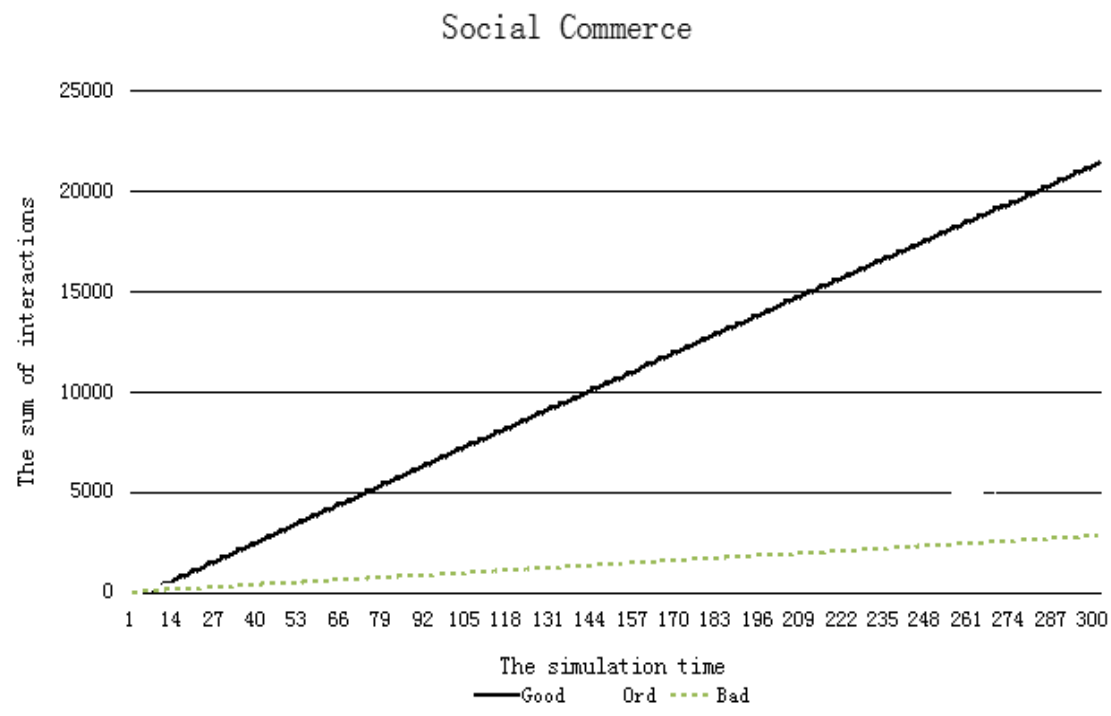

Figure 5. The Total Trading Volume (Social Commerce, Simulation Time of 300)

Social Commerce

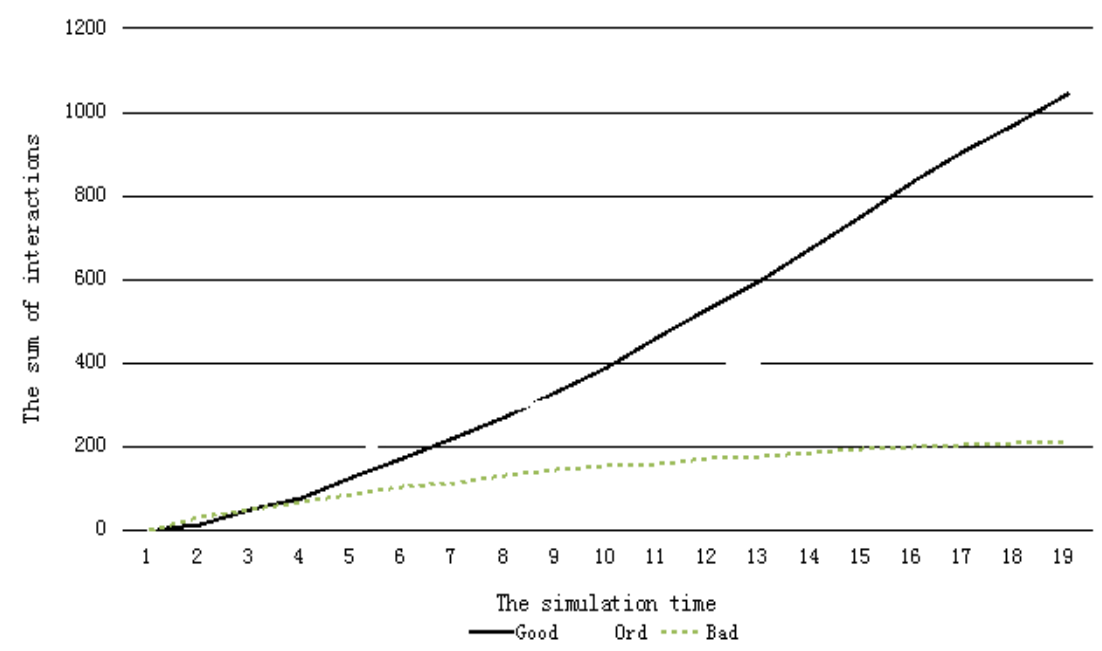

Figure 6. The Total Trading Volume (Social Commerce, Simulation Time of 20)

In s-commerce situation, high-quality merchant can succeed all the others with greater rapidness in the sales, establishing competitive advantage as shown in Figure 5 and Figure 6 . With the obviousness of group's convergence in s-commerce, consumers generally choose the high-quality merchants rather than others due to the service quality gap (even though there was so little difference between the normal and the high-quality in service). That is because consumers in s-commerce can rapidly locate high-quality merchants. And with the widening spread of one or more consumers' evaluation information in social 
network, the credit evaluation of all the consumers in this network has been affected. It is a spread of social influence.

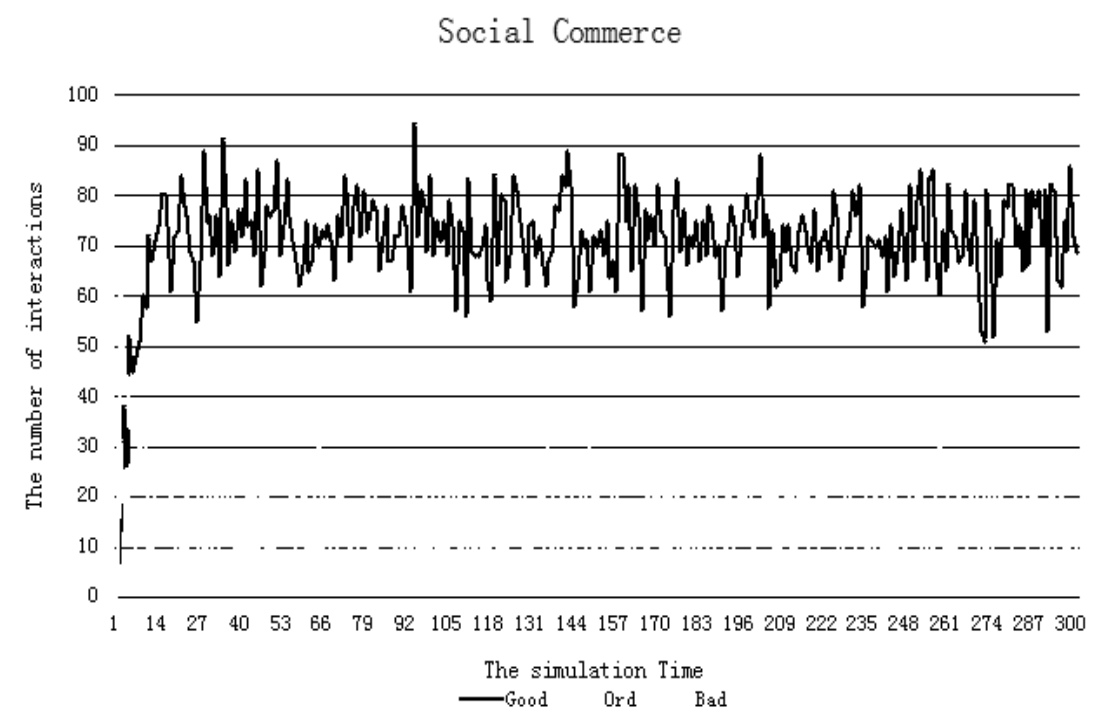

Figure 7. The Volatility of Transaction Times (Social Commerce)

The superiority of high-quality merchants in the number of consumers is more significant and the number of consumers grows much faster in early phase as shown in Figure 7, proving the phenomenon in Figure 5 and Figure 6 on the other hand: In the context of social commerce, although as with traditional e-commerce the number of transactions served by quality merchants is rising up in the beginning, in s-commerce situation consumers can distinguish the type of business at great speeds. In mid to late stage, there are fluctuations in the number of consumers served by all types of merchants within a fixed range, but quality merchants have distinct advantages in the number of transactions compared to other merchants. This means not only dominated in total sales, quality merchants have significant difference on income each phase. In the perspective of influence on consumer buying behavior from information sharing, social commerce, not only having the characteristics of traditional e-commerce, but also has some new features. Two features can be summarized: a) compared with traditional e-commerce, consumers in s-commerce can update their evaluation library faster and locate quality merchants more rapidly; b) quality merchants in social commerce can expect to gain more market share, while ordinary merchants have almost the same market share as bad merchants, even if taking advantage in quantity and quality.

4.2.3. The Comparative Analysis on The Causes of Social Commerce Properties: This paper proposes one of the causes of consumer buying behavior characteristic in scommerce, is that under social commerce context, the transmission of evaluation information is the entire social network. When one or more consumers adopt exploring strategy, all the consumers would react to this action. For example, if after adopting a strategy one or more consumers are served well above the expectation average, others may adopt this strategy as well, resulting in the enlargement of the fluctuation of transaction times. The social influence has direct impact on behavior of consumers in social commerce [21-22].

Secondly, although the query chain length in social commerce is longer than traditional e-commerce, the maximum number of people each consumer can query has not changed (in social commerce, the maximum number of people each consumer can query is 
$\left.n_{B F} *\left(n_{B F}+1\right)=12\right)$. So the change in the length of the query chain has been linked with consumer behavior characteristics. Therefore the cause of these features is not just that consumers in s-commerce can share information with more people [23]. The result of simulation when changing the Parameter $\mathrm{H}$ in traditional e-commerce $(\mathrm{H}$ is changed to 30) is shown in Figure 8 and Figure 9.

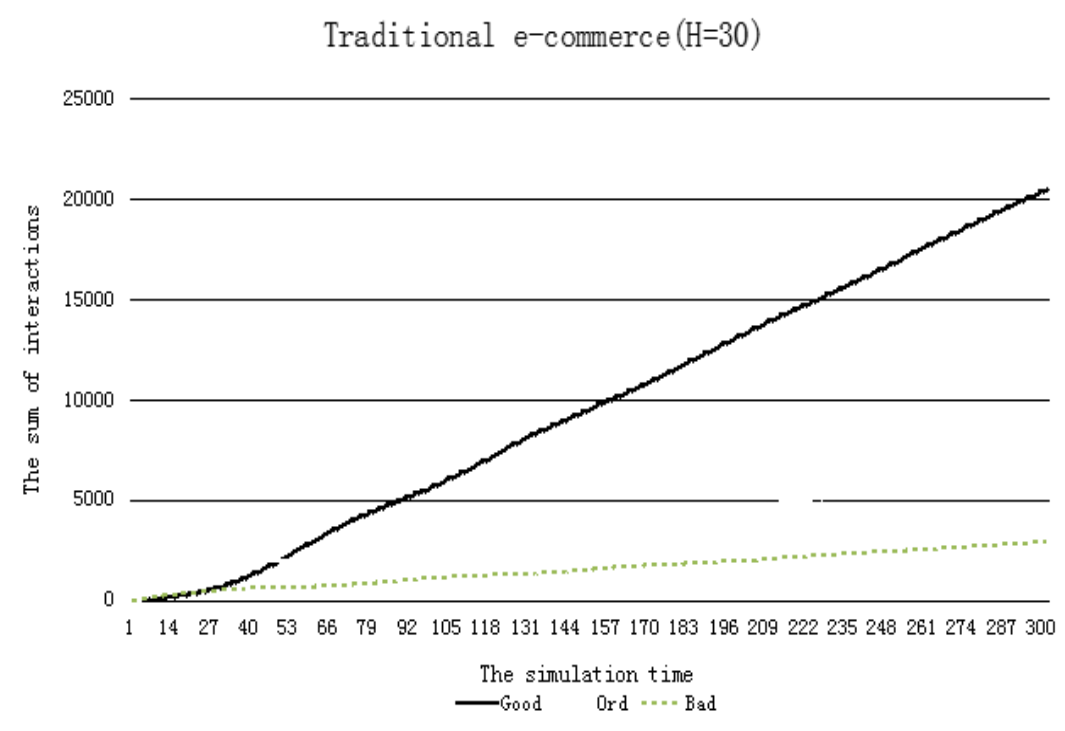

Figure 8. The Total Trading Volume $(\mathrm{H}=30)$

Traditional E-Commerce $(\mathrm{H}=30)$

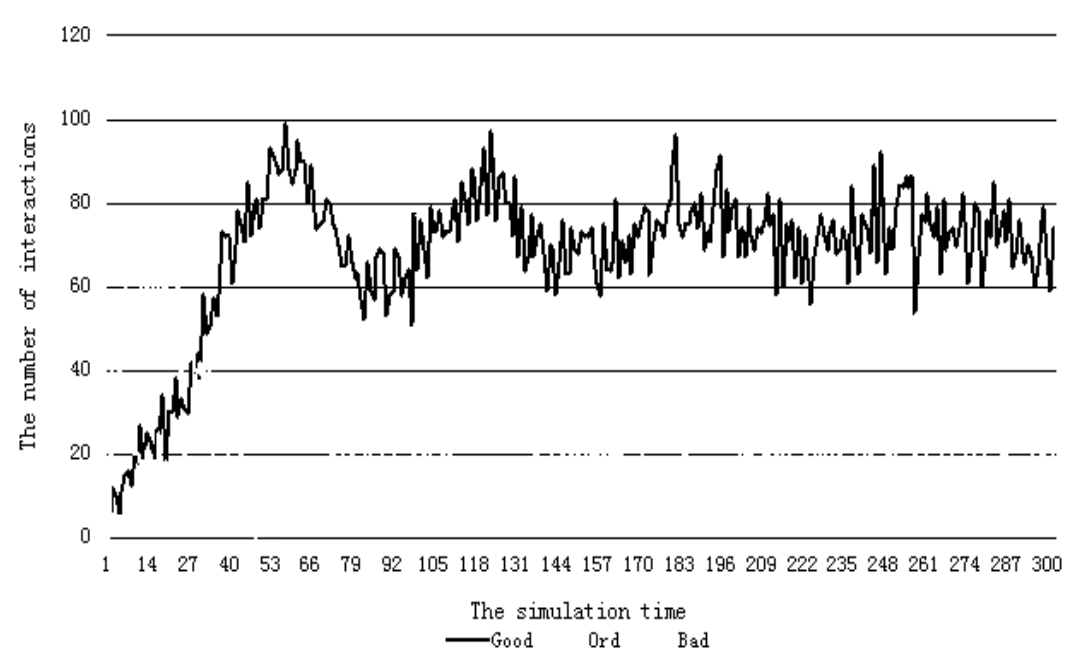

Figure 9. The Volatility of Transaction Times $(\mathrm{H}=30)$

Through the simulation results in Figure 8 and Figure 9, we can see that although the mode of information sharing is different, with the increasing of the parameter $\mathrm{H}$, consumers' behavior in traditional e-commerce exhibited characteristics in social commerce: faster locating quality merchants and domination of quality merchants in market share. In this study, the parameter $\mathrm{H}$ represents the maximum number of evaluation information each consumer can memory. In other words, when consumers in traditional e-commerce have comprehensive enough awareness about environment, it is 
possible to make the same purchasing decisions with consumers in s-commerce, but this "comprehensive" is essentially a very ideals and unrealistic state. On the other hand, it means social commerce offers a more social, interactive, and collaborative online experience, where collective intelligence can be aggregated and used to support customers' problem solving and decision making[24]. The value created by customers is significantly enhanced through social media since the collaborative efforts of networked customers usually lead to better outputs [25].

\section{Conclusions and Future Work}

This paper analyzes the influence of sharing evaluation information on consumer's choice of buying in s-commerce by a method of multi-agent simulation based on FIRE model. It has many advantages, such as avoiding the limitations of problems like difficulty in traditional research data collection and second inference. Using multi-agent simulation method to study the dynamic sharing of information in s-commerce is to overcome limitations of static analysis, and at the same time it also provides a new approach to study the influence of sharing information on consumer's behavior.

The information-based simulation model of consumer behavior in s-commerce has fully considered the impact of context and sources of information and set up rules on consumer decision of purchase on the basis of consumer sub-model and vendor submodel, realized the simulation for two different information sharing situation by using Repast. The simulation results show that information-sharing model in s-commerce is enabling consumers to locate the merchant which can provide quality goods or services faster than ever, and the gap in market share caused by the difference among the quality of goods or services is further amplified in s-commerce. Due to large fluctuation of the number of transactions, one or multiple evaluation information in social network will affect other consumers' strategy selection and credit assessment throughout the network.

In summary, in formulating s-commerce merchants strategy, this study suggests that merchants should focus on how to keep the quality of services or goods on a stable level, because the decrease in service level leads to the following declines in sales and revenues for the improvement of locating quality merchants. And merchants should add commodity's characteristics: high cost or innovation, in order to gain more market share in social commerce environment and establish greater competitive advantage. So, there are more requirements on merchants' service in s-commerce. Traditional speculation such as fast forging the number of praises to gain huge short-term profits is no longer working. A successful merchant in s-commerce should have the ability of responding quickly to market changes (such as changes in consumer demand). And this study suggests that on the basis of this study, the influence on consumer buying behavior of less accurate evaluation information may be further studied to provide further advices on advertising and business strategies of merchants in the social commerce.

On other hand, the multi-agent simulation system for social commerce can visualize the interactions among users at micro-level, and present macro-level insights about group behavior in the end. The findings derived from the macro-level and the micro-level in this model can help other researchers attain evolutionary data in different situation settings. These agent-based models have proven to be useful for understanding social interaction dynamics in social commerce. Above all, this study suggests the people who want to get into this field should focus on the role of spread of social influence in social commerce from a dynamic point of view, as well as behavior of consumers or correlation study.

In this study, there are still many limitations. Firstly, the merchant sub-model is too simple to fully reflect the changes of merchants' behavior in social merchant. Secondly, the model does not consider role-based trust and certification trust, and the research on relevant sources of information is not deep enough. Thirdly, customer classification is too simple. It does not consider different customers' tendency and the formation of their 
social relationships, just randomly processing the formation of relationships. Finally, it does not consider the influence of the credibility of evaluation information on social relationships, and this is an emphasis direction of future research.

\section{Acknowledgements}

The authors thank two anonymous reviewers for their detailed, insightful comments. We also thank Qingping Yang and Hao Zhang for valuable comments on an earlier draft of the paper.

\section{References}

[1] T. P. Liang and E. Turban, "Introduction to the special issue social commerce: a research framework for social commerce", International Journal of Electronic Commerce, vol. 16, no. 2 (2011).

[2] C. Wang and P. Zhang, "The evolution of social commerce: The people, management, technology, and information dimensions", Communications of the Association for Information Systems, vol. 31, no. 5, (2012).

[3] S. Sharma and R. E. Crossler, "Disclosing too much? Situational factors affecting information disclosure in social commerce environment", Electronic Commerce Research and Applications, (2014).

[4] M. Anderson, J. Sims, J. Price and J. Brusa, "Turning "Like" to "Buy" social media emerges as a commerce channel", Booz \& Company Inc., (2011).

[5] S. J. Yu, "The dynamic competitive recommendation algorithm in social network services", Information Sciences, vol. 187, (2012).

[6] Y. M. Li, H. W. Hsiao and Y. L. Lee, "Recommending social network applications via social filtering mechanisms", Information Sciences, vol. 239, (2013).

[7] T. P. Liang, Y. T. Ho, Y. W. Li and E. Turban, "What drives social commerce: the role of social support and relationship quality", International Journal of Electronic Commerce, vol. 16, no. 2, (2011).

[8] M. Trusov, R. E. Bucklin and K. Pauwels, "Effects of word-of-mouth versus traditional marketing: findings from an internet social networking site", Journal of marketing, vol. 73, no. 5, (2009).

[9] H. L. Wu and J. W. Wang, "An empirical study of flow experiences in social network sites", (2011).

[10] T. D. Huynh, N. R. Jennings and N. R. Shadbolt, "An integrated trust and reputation model for open multi-agent systems", Autonomous Agents and Multi-Agent Systems, vol. 13, no. 2, (2006).

[11] A. Das and M. M. Islam, "Securedtrust: a dynamic trust computation model for secured communication in multiagent systems", Dependable and Secure Computing, IEEE Transactions on, vol. 9, no. 2, (2012).

[12] F. Skopik, D. Schall and S. Dustdar, "Modeling and mining of dynamic trust in complex service-oriented systems", Information Systems, vol. 35, no. 7, (2010).

[13] P. Leitner and T. Grechenig, "Scalable social software services: towards a shopping community model based on analyses of established web service components and functions", System Sciences, HICSS'09 42nd Hawaii International Conference on IEEE, (2009).

[14] J. Choi, H. J. Lee and Y. C. Kim, "The influence of social presence on customer intention to reuse online recommender systems: The roles of personalization and product type", International Journal of Electronic Commerce, vol. 16, no. 1, (2011).

[15] D. J. Kim, D. L. Ferrin and H. R. Rao, "A trust-based consumer decision-making model in electronic commerce: The role of trust, perceived risk, and their antecedents", Decision support systems, vol. 44, no. $2,(\mathbf{2 0 0 8})$.

[16] H. H. Chang and S. W. Chen, "The impact of online store environment cues on purchase intention: Trust and perceived risk as a mediator", Online Information Review, vol. 32, no. 6, (2008).

[17] H. Zhang, Y. B. Lu, S. Gupta and L. Zhao, "What motivates customers to participate in social commerce? The impact of technological environments and virtual customer experiences", Information \& Management, (2014).

[18] G. W. Bock, J. Lee, H. H. Kuan and J. H. Kim, "The progression of online trust in the multi-channel retailer context and the role of product uncertainty", Decision Support Systems, vol. 53, no. 1, (2012).

[19] E. Bakshy, I. Rosenn, C. Marlow and L. Adamic, "The role of social networks in information diffusion", Proceedings of the 21st international conference on World Wide Web, ACM, (2012).

[20] P. Hui and Y. R. Wang, "Research of C2C e-commerce sellers' credit distribution", Journal of Intelligence, vol. 31, no. 5, (2012).

[21] J. Li, W. Peng, T. Li, T. Sun, Q. Li and J. Xu, "Social network user influence sense-making and dynamics prediction", Expert Systems with Applications, vol. 41, no. 11, (2014).

[22] R. K. Jain, R. Gulbinas, J. E. Taylor and P. J. Culligan, "Can social influence drive energy savings? Detecting the impact of social influence on the energy consumption behavior of networked users exposed to normative eco-feedback", Energy and Buildings, vol. 66, (2013).

[23] Z. Huang and M. Benyoucef, "User preferences of social features on social commerce websites: An empirical study", Technological Forecasting and Social Change, (2014). 
[24] Z. Huang, S. Y. Yoon and M. Benyoucef, "Adding Social Features to E-commerce", Proceedings of the Conference on Information Systems Applied Research ISSN, (2012).

[25] A. M. Kaplan and M. Haenlein, "Users of the world, unite! The challenges and opportunities of Social Media", Business horizons, vol. 53, no. 1, (2010).
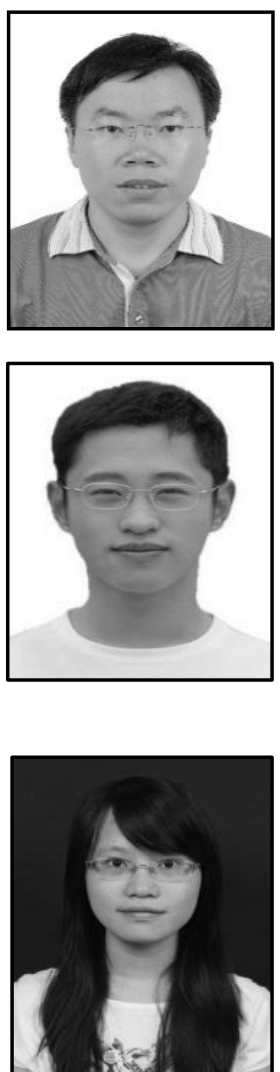

Dan Liu, is a Master student in the School of Information Technology at the Jiangxi University of Finance and Economics. She received her Bachelor of Management degree in the same school at the same university in 2013. Her research focuses on knowledge sharing and transferring. She is a student member in Information Resources Management Lab. She can be reached by email at <ldfrency@126.com>. 
International Journal of $u-$ and e- Service, Science and Technology Vol.8, No. 6 (2015) 